DOI: 10.11606/issn.2238-3867.v16i1p82-91

sala preta

ppgac

Dossiê Performatividades Originárias

\title{
Memória e ancestralidade: lastros que ecoam e escoam na contemporaneidade
}

Memory and ancestrality:

traces that echo and spread in contemporaneity

\section{Célia Regina Gouvêa Vaneau}

Celia Regina Gouvêa Vaneau

Coreógrafa formada pelo Centro Europeu de Aperfeiçoamento

e Pesquisa dos Intérpretes do Espetáculo (Mudra, de Maurice Béjart) e doutoranda no Programa de Pós-graduação da Escola de Comunicações e Artes da Universidade de São Paulo (ECA-USP)

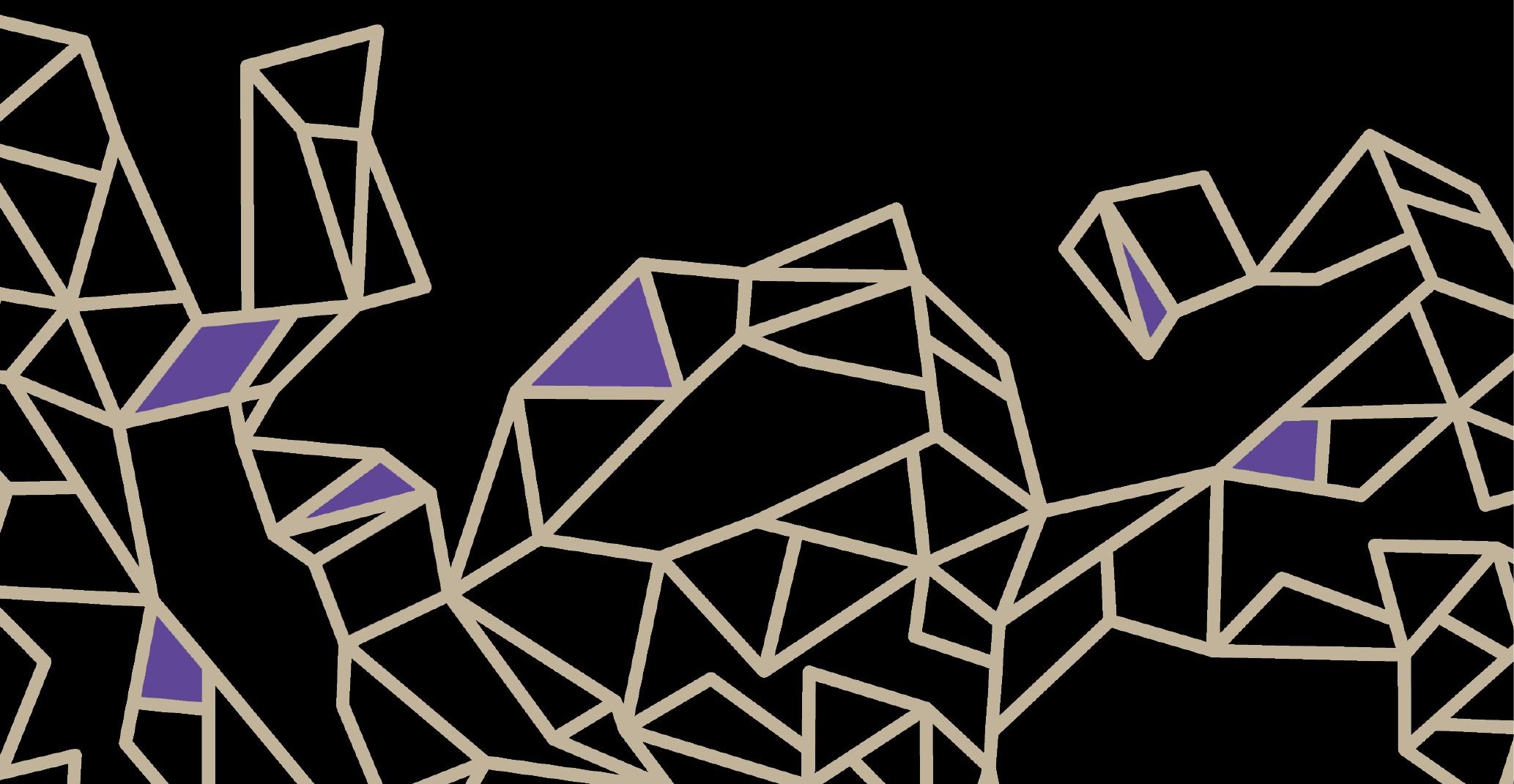




\section{Resumo}

O presente artigo propõe uma reflexão quanto à transformação de parâmetros, quando o predomínio do procedimento conceitual cede à emergência da memória, ou aquilo que está inscrito no corpo; questiona a existência de núcleos culturais preservados e evita a dualidade entre central e periférico. A partir de eventos observados em certas regiões do Brasil, encontra a fértil via da ancestralidade, presente em instâncias várias da produção artística. Os argumentos são sustentados, entre outros, pelo pensamento dos encenadores Jerzy Grotowski e Peter Brook, dos teóricos Henri Bergson e Walter Benjamin e do neurocientista Antonio Damasio.

Palavras-chave: Memória, Ancestralidade, Conexão, Corpo.

\section{Abstract}

This article proposes a reflection about the transformation of parameters, when the predominance of the conceptual procedure gives way to the emergence of memory, or to what is inscribed on the body. It questions the existence of preserved cultural centers and avoids the duality between central and peripheral. From events observed in certain regions of Brazil, it finds the fertile way of ancestrality, which is present in multiple instances of artistic production. The arguments are supported, among others, by the thought of the theater directors Jerzy Grotowski and Peter Brook, theorists Henri Bergson and Walter Benjamin and neuroscientist Antonio Damasio.

Keywords: Memory, Ancestrality, Connection, Body.

É possível hoje encontrar núcleos culturais preservados? Considero pouco provável, onde quer que seja, devido ao constante movimento e consequente transformação, conforme admitido desde o século VI a.C. por Heráclito de Éfeso, que considerou a instabilidade, o movimento e o devir como motores de todas as coisas, em detrimento do que é estático. Coreógrafos do século XX, Alwin Nikolais e Merce Cunningham consideraram todos os pontos do espaço igualmente importantes, não privilegiando o centro. Ao contrário, um potente ponto periférico pode tornar-se centro. $O$ mesmo pode ser considera- 
do acerca do hemisfério norte em relação ao hemisfério sul. O propósito de escapar a qualquer dicotomia e maniqueísmo leva a ater-me a alguns eventos que presenciei no Brasil.

A palavra "internacional" foi acrescida ao hoje denominado Festival Internacional do Folclore de Olímpia, cidade situada no interior do estado de São Paulo, distante cerca de 500 quilômetros da capital. Em 2014 completou seu quinquagésimo aniversário, e no dia do encerramento do festival, sempre aos domingos, grupos parafolclóricos desfilam em carros alegóricos na principal avenida da cidade. O evento, realizado sempre no mês de agosto, apresenta uma extensa variedade de folguedos e em sua última edição atraiu aproximadamente 30 mil pessoas. Suas primeiras edições aconteciam na Praça da Matriz. Posteriormente, um folcloródromo com palco foi construído, no qual os grupos se apresentam, o que estabelece uma distância com o público. O momento mais vibrante é a preparação dos grupos que antecede as apresentações, quando circula mais energia. Muitos brincantes pintam o rosto de azul, com anil. O recurso, bem como máscaras trazidas de Pirenópolis, foi assimilado em nossa montagem de Festarola1.

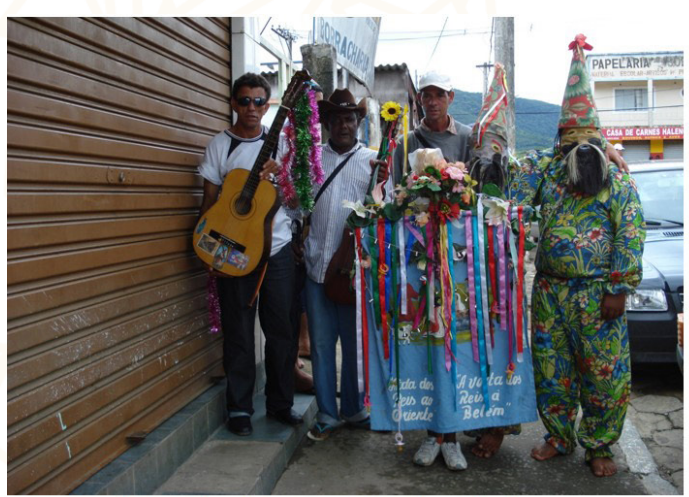

Folia de Reis. Minas Gerais, 2009.

Foto: Célia Gouvêa.

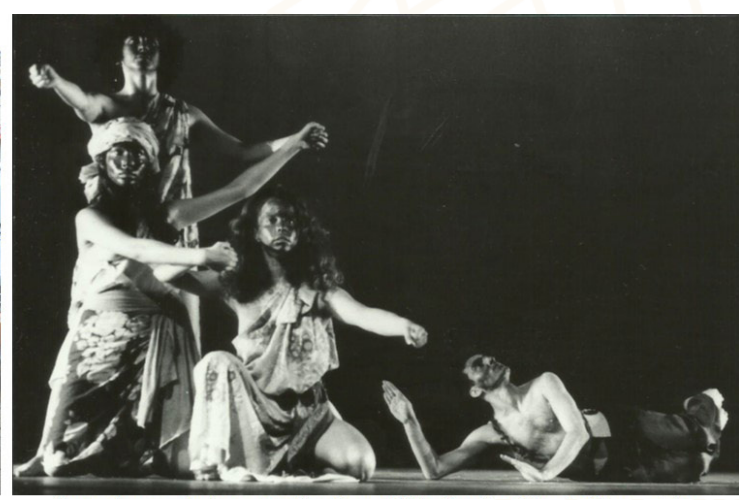

Festarola, peça de dança coordenada por Célia Gouvêa e Maurice Vaneau. Foto: Gil Grossi, 1989. À frente, Helena Bastos e João Andreazzi.

1 No final dos anos 1980 realizamos o projeto "A Identidade da Dança Nacional" com apoio do CNPq, quando procedemos a uma ampla pesquisa das danças populares brasileiras, provenientes de várias regiões do Brasil. O produto cênico foi a peça de dança Festarola. 
Por seu lado, o Festival de Parintins, no Amazonas, é hoje um megaevento que parece mirar-se nos desfiles das escolas de samba do Rio de Janeiro e conta com ampla cobertura da mídia. Num tempo de capitalismo avançado, quando as regras do mercado permeiam todas as esferas da vida, o autêntico, entendido no sentido heideggeriano como afirmação do ser, poderá ser encontrado sim, mas mesclado inevitavelmente aos frutos da globalização. Os jovens que pisavam as ruas pavimentadas com paralelepípedos em $\mathrm{Pi}$ renópolis, à noite frequentavam a boate Maromba, cujo repertório musical pouco diferia de qualquer outra cidade.

Inquestionável é a pulsão que emana dos mascarados montados a cavalo, portando guizos e panos floridos durante a Festa do Divino em Goiás, na citada cidade de Pirenópolis, por exemplo. Misturam materiais brilhantes à sucata - palhas, folhas secas, sacos de estopa e outros, num processo de bricolagem. Suas máscaras, feitas em papel machê, remetem a bichos chifrudos ou homens narigudos. Pedem dinheiro aos turistas para depois tomar cerveja. Remetem aos mouros e são chamados "os espiões das cavalhadas". Evento de tradição ibérica, leia-se árabe, em seus primórdios as cavalhadas abrilhantavam datas comemorativas como casamentos reais, e foram posteriormente circunscritas à esfera da burguesia. As cavalhadas foram também o gatilho para a instauração dos torneios equinos na Espanha. Os mascarados de Pirenópolis surgem ao lado da igreja no sábado, antecedendo o enfrentamento gentil entre mouros vestidos de vermelho e os cristãos em cor azul, cujo confronto ocorre na cidade aos domingos durante a Festa do Divino Espírito Santo desde 1819, não lembrando em nada os combates hostis do tempo das cruzadas, entre os séculos XI e XIII.

Igualmente de procedência ibérica, outro exemplo é a Folias de Reis, auto popular religioso e profano, composto por músicos, cantores e dançadores das capitais e centros urbanos. Descalços, portam máscaras e vestes coloridas, geralmente confeccionadas com chita. Considerados soldados de Herodes, têm, assim, "parte com o diabo", e podem ser observados principalmente em cidades do estado de Minas Gerais. A Folia de Reis tornou-se um evento autônomo, já não muito importando o anúncio da chegada do messias e a homenagem aos três reis magos - Gaspar, Melquior e Baltasar -, que, trazendo ouro, incenso e mirra, correspondem respectivamente à inspeção, à 
luz e à manifestação. Os participantes, observados por profissionais das artes cênicas, poderão estimular seu imaginário.

$\mathrm{Na}$ internet, como outro exemplo, surgem a todo momento crianças de aldeias africanas dançando, que têm enorme sentido do movimento e contato com o chão, com a terra, mas lá está a câmera postada, e os dançadores que aguardam a sua vez, bem como os que assistem, encontram-se simetricamente posicionados.

O que pulsa, quer nos eventos descritos, quer numa determinada vertente da arte contemporânea, é o gosto à alteridade, a atração por adquirir novos contornos corporais, por meio do paramento e do adorno, de modo a escapar ao cotidiano e romper as regras da rotina, o que embute a necessidade de transformação, que conduz ao adentramento em tempos mais alargados, que carregam componentes míticos e simbólicos. Narrativo, icônico ou ambos, o mito remete à memória coletiva e acende seu imaginário. Simbale em grego é "reunir". A palavra símbolo carrega o prefixo "sim", que vem do grego syn e significa "colocar junto", o equivalente a "junção" ou "conexão". Resultado de relações, opera aproximações. Envolve também uma consciência cósmica, que desloca o antropocentrismo habitual. Silenciosa ou sonora, toda ação repetida é ritual. O ritual pode ser sagrado ou fazer parte da rotina. Até mesmo o processo de elaboração de um artigo, o percurso das várias etapas até o envio, é ritual. Para o escritor, professor e homem de teatro Richard Schechner (2006), "Rituais são memórias coletivas codificadas em ações" (p. 52).

O escritor venezuelano Fernando Báez (2010), após examinar o complexo conceito de identidade, processo inextinguível segundo o autor, e relevar o sentido de pertencimento, diz: "As recordações compartilhadas costumam ser aglutinantes e são a base das memórias que permitem falar de uma história comum" (p. 286).

É por ação da faculdade da memória que um conhecimento adormecido aflora, manifesta-se, desoculta-se. Revelado, torna-se ato, o que requer, nas palavras de Martin Heidegger, "estar dilatado e estendido na amplidão de si mesmo" (apud BRACHTENDORF, 2008, p. 267), ou seja, é necessário afrouxar as malhas do tempo. As palavras de Heidegger ecoam o que já havia sido colocado por Henri Bergson. Seu conceito de duração supõe trazer para o presente algo que já não existe mais, através de um ato de presentificação. 
Se o tempo cronológico é metrificado, o tempo extenso não o é: "a duração real é o que sempre se chamou tempo, mas o tempo percebido como indivisível" (BERGSON, 2006, p. 16). Para o pensador francês, a memória não se encontra no cérebro. Ele admite a existência desse lugar nenhum, não localizado. Munido de ferramentas mais recentes, Antonio Damasio (2011), após considerar que a memória é decorrente de tudo o que se percebe no ambiente, odores inclusive, e após estabelecer interfaces entre a memória, a imaginação e a criatividade, topografará uma arquitetura do cérebro, exaltando suas proezas: "cria registros de memórias dos mapas sensoriais e reproduz uma aproximação de seu conteúdo original. Esse processo é conhecido como recall ou evocação" (p. 173). As neurociências vêm encontrando novas plasticidades para o cérebro, distintas do uso cotidiano, ultrapassando-o, indo além. Damasio (2011) acrescentará que "a percepção ou evocação da maioria dos objetos e eventos depende de atividade em várias regiões cerebrais formadoras de imagem e envolve também partes do cérebro relacionadas ao movimento" (p. 191).

Jerzy Grotowski (1987) não incentivava a busca à cata do novo: "Eu não procuro descobrir algo novo, mas algo esquecido" (p. 1). Para o encenador polonês, um dos acessos ao caminho criativo consiste em descobrir dentro de si uma antiga corporalidade à qual se esteja ligado por uma forte relação ancestral. O corpo fornece o canal através do qual o sutil é tocado e no qual as energias circulam e transformam-se. A respiração e a voz, presenças importantes nas encenações de Grotowski, acompanham tal concepção. O teatro, enquanto ato que se cumpre aqui e agora no organismo do ator, segue uma direção "a-lógica, quase invisível e intangível" (Id., 1971, p. 86)². Seguindo a mesma orientação de pensamento, o encenador Peter Brook (1968) denominou teatro sagrado ao invisível tornado visível e escreve acerca do ator - "se ele está relaxado, aberto e conectado, então o invisível tomará posse dele; através dele, ele irá nos atingir". E conclui: "nós estamos redescobrindo que um teatro sagrado é ainda o que nós precisamos. Então, onde procurá-lo? Nas nuvens ou no chão?" (Ibid., p. 47 e 72). Brook buscou na África e na Ásia pontes e reciprocidades para a construção de sua linguagem cênica,

2 As reflexões aqui desenvolvidas constam da pesquisa de doutorado em andamento "Mudra e Galpão: experiências cênicas interlinguagens". 
a exemplo de outros encenadores europeus na primeira e segunda metade do século XX, como Antonin Artaud, sacudido que foi pelo teatro não verbal balinês, ou Ariane Mnouchkine, que encontrou no teatro asiático soluções formais que procurava.

Tal vertente é um contraponto ao predomínio de uma arte conceitual, que num passado recente marcou presença entre nós. Surgida nas artes visuais dos anos 1960, nasce do construto intelectual, em detrimento da aisthesis ou sensação. O conceitualismo pode ser observado nas artes cênicas desde os anos 1980 e na dança, principalmente, nas décadas de 1990 e 2000. Ater-se ao entorno com agudez e gerar conceitos teve como precursor Marcel Duchamp. Seguiu-se, por exemplo, "Arte como Ideia" de Joseph Kosuth, que se serviu de um quadrado negro para descrever a ação de pintar, em cinco itens. O termo conceitual foi paulatinamente definido: primeiro em 1961 por Henry Flynt do Grupo Fluxus (concept art ou arte do conceito), depois em 1963 por Edward Kienholz (concept tableaux ou quadros conceituais) e finalmente em 1967 por Sol Lewitt. Ao priorizar o conceito, tampouco os artistas conceituais guardaram a noção hegeliana de que a arte é a materialização sensível da ideia, mas sim uma construção. Nicolas Bourriaud (2009) referiu-se "ao modo analítico e desconstrutivo da arte conceitual" (p. 107).

Não se trata de combater o logocentrismo ocidental, ainda mais se levarmos em conta o vocábulo logos como equivalente a sentido. A atenção à produção artística contemporânea leva a constatar que não há incompatibilidade, uma vez que as questões referentes à organização e estrutura estarão sempre presentes, mas o que há é a ênfase em outros procedimentos. É inquestionável que, no Modernismo, músicos como o russo Igor Stravinski, o húngaro Bela Bartok, o francês Claude Débussy e o brasileiro Heitor Villa Lobos recolheram materiais provenientes do tecido vivo, geralmente anônimo, de seus povos, e os transformaram, por meio de um processo de filtragem e reelaboração. Munidos de seus conhecimentos compositivos, afirmaram as celebradas pontes entre o arcaico e o moderno, o erudito e o popular.

Grande viajante, o escritor, musicista e intelectual Mário de Andrade classificou exaustivamente o que intitulou Danças dramáticas do Brasil (1982). O escritor, musicista e intelectual atribuiu a três vertentes a procedência das danças: a primeira delas é o cortejo, amplamente empregado em montagens 
teatrais contemporâneas. A palavra soa derivada de corte, mas sua procedência é bem mais remota, desde os primórdios do teatro grego. A afirmação de Friedrich Nietzsche em O Nascimento da Tragédia no Espírito da Música, quanto ao nascimento do Teatro na Grécia será recebida em concordância;

[...] cerimônia religiosa celebrando um rito agrário ou de fertilidade, inventando roteiros nos quais um deus morreria para melhor reviver, um prisioneiro é condenado à morte, uma procissão, uma orgia ou um carnaval eram organizados entre os gregos. A tragédia proveria do culto dionisíaco e do ditirambo (PAVIS, 1999, p. 345).

Segundo Mário, a procedência dos cortejos remonta às tradições pagãs de Janeiras e Maias, as tradições profanas cristãs das corporações proletárias e outros, os cortejos reais africanos e as procissões católicas com folias de índios, pretos e brancos, seguidos pelos bem comportados pastoris e "finalmente os brinquedos populares ibéricos, celebrando as lutas de cristãos e mouros" (ANDRADE, 1982, p. 33). Mário de Andrade e os compositores citados não podem ser considerados forasteiros que partiram para realizar suas pesquisas a fim de se apropriarem de material alheio, mas encontravam-se já habitados pela matéria na qual buscavam alimento. $\mathrm{O}$ que confere clareza e elucida a questão tratada é a noção de conexão, que evita o discurso separatista entre cultura erudita e popular, e conduz da fértil via da memória ao seu próprio entendimento.

O contexto imediato da palavra tradição remete a algo estático, coercitivo e obediente. Contudo, pode se ligar àquilo que o nosso corpo-memória armazena e onde se reconhece, pode remeter a um universo mítico com conotações ancestrais, estranho ao ditame de regras. Em "O Narrador", Walter Benjamin distingue a vivência, algo ocasional, da experiência, que é transmitida e deixa heranças. O autor alemão dirá: "o narrador empresta a matéria de seu relato à experiência. E o que ele conta, por sua vez, torna-se experiência naqueles que escutam sua história" (BENJAMIN, 2000, p. 120-121).

Trata-se de reconhecer a via de um trabalho orgânico. A palavra "orgânico" vem sendo frequentemente esbanjada, sem que se atente suficientemente aos seus atributos. A atenção aos órgãos não caminha sozinha, mas requer a concentração na estrutura interna do corpo. O aparato psíquico e 
sensório-motor, os canais cinestésicos ligados à sensação em movimento são acionados, gerando a conexão consigo, orientando um modo de interagir com o mundo e ser por ele afetado. Conexão é a palavra-chave, que inclui o contato com o outro e com o ambiente, podendo envolver cores, máscaras, artesanias - legados resultantes do atravessamento entre interioridade e entorno. Há fenômenos míticos que, a exemplo dos palimpsestos, deixam lastros. As malhas entre as manifestações chamadas periféricas e centrais tecem-se conjuntamente. A perversa globalização que o diga.

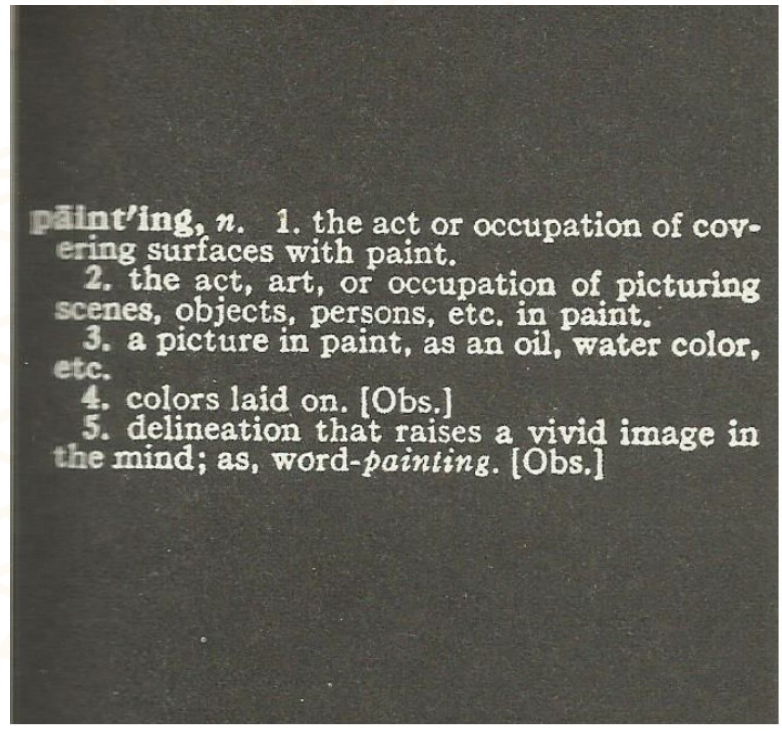

Protótipo do Conceitualismo. Joseph Kosuth "Art as Idea." 1966.

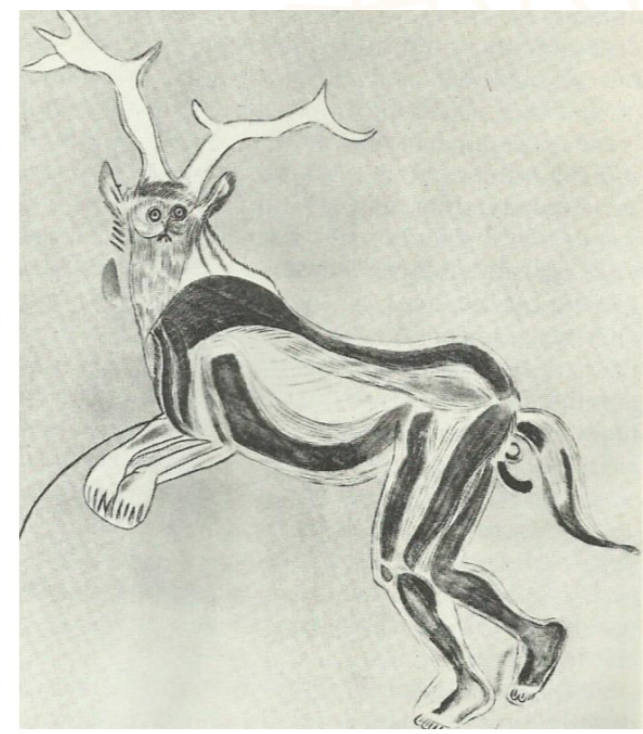

Imagem de ancestralidade. Deus chifrudo (ou homem fantasiado de animal). Desenho de gruta pré histórica na região da França do Rio Volpe. In History of Theatre, de Oscar G. Brockett.

\section{Referências bibliográficas}

ANDRADE, M. Danças dramáticas do Brasil. 2. ed. Belo Horizonte: Itatiaia, 1982. BÁEZ, F. A História da destruição cultural da América Latina: a identidade cultural. São Paulo: Nova Fronteira, 2010.

BENJAMIN, W. Oeuvres III. Paris: Gallimard, 2000.

BERGSON, H. Memória e vida. Tradução Cláudia Berliner. São Paulo: Martins Fontes, 2006.

BOURRIAUD, N. Estética relacional. Tradução Denise Bottmann. São Paulo: Martins Fontes, 2009. 
BRACHTENDORF, J. Confissões de agostinho. São Paulo: Loyola, 2008.

BROOK, P. The empty space. Midlesex: Penguin, 1968.

DAMASIO, A. E o cérebro criou o homem. Tradução Laura Teixeira Motta. São Pau-

lo: Companhia das Letras, 2011.

GROTOWSKY, J. Vers um théâtre pauvre. Lausanne: La Cité, 1971.

Encontros à volta da performance. Tradução Thomas Richards e João

Garcia Miguel. Paris: Art Press, 1987.

PAVIS, P. Dicionário de teatro. Tradução J. Guinsburg e Maria Lúcia Pereira. São

Paulo: Perspectiva, 1999.

SCHECHNER, R. Performance studies: an introduction. 2. ed. New York; London:

Routledge; Taylor \& Francis Group, 2006.

Recebido em 22/04/2016

Aprovado em 17/05/2016

Publicado em 01/07/2016 